\title{
Indwelling Catheter
}

National Cancer Institute

\section{Source}

National Cancer Institute. Indwelling Catheter. NCI Thesaurus. Code C54729.

A hollow tube left implanted in a body canal or organ, especially the bladder, to promote drainage. 